\title{
How to recognize patients at risk or infected with HIV
}

This monthly series was developed from the AOA Task Force on AIDS Writers' Workshop, held August 16 to 18, 1991, in New York. The workshop was sponsored by an educational grant from Burroughs Wellcome. It will provide brief clinical updates and perspectives on the human immunodeficiency virus (HIV). Readers may request tear sheets from the AOA editorial offices.

(Key words: AIDS, HIV infection, HIV transmission, infection control, communicable diseases)

\section{Question}

How can I better recognize patients in my practice who are at risk, or perhaps, who are already infected with HIV?

\section{Answer}

It is estimated that more than 1 million Americans are infected with the human immunodeficiency virus (HIV), and all 50 states have reported cases. Such prevalence means that most physicians have or will see patients or families affected by this virus. Consequently, recognition of HIV infection is an important goal of medical care, both to effect behavior modification and to initiate antiretroviral therapy when indicated. To determine who should be tested, you can identify those at risk by taking a careful history and performing a thorough physical examination.

Questions regarding sexual practices and drug use are sensitive and personal, so they can be uncomfortable not only for the patient but also for the inquiring healthcare worker.
Because the predominant mode of HIV transmission in the United States is sharing body fluids during sexual activity and injection of illicit drugs, it is essential to elicit such information from patients to identify those persons potentially infected by the HIV. Several techniques are helpful for putting the patient at ease, but only practice and perseverance will help the uncomfortable healthcare worker adjust to such intimate inquiries.

The following five sample questions can help you to identify those patients at risk not only for HIV infection but also for other sexually transmitted diseases.

- Are your sexual partners men, women, or both?

- Have you had unprotected oral, anal, or vaginal sex with multiple partners?

- Have you had sex with a high-risk partner, for example, an intravenous drug user, a bisexual male, any person having multiple sexual partners, a prostitute, et cetera?

- Have you had genital ulcers or other sexually transmitted illnesses, for example, genital warts, herpes, gonorrhea, syphilis?

- Have you ever used intravenous drugs, and, if so, did you ever share needles with someone?

Don't ask these questions first, but rather integrate them in the history-taking process during the genitourinary review. Be nonjudgmental in tone and manner when you ask these questions. You can help to reassure the patient by preceding the questions with a brief explanation of their importance in providing the best medical care. Asking such questions gives the patient "permission" to discuss information that is of great importance, both in personal 
relationships and healthcare, but is seldom volunteered because of its sensitive nature.

If the patient is involved in a high-risk behavior and is HIV-antibody-negative, counseling may effect behavior modification and disease prevention. You can institute therapy only after case identification. Carefully posed questions are critical to identifying those patients at risk for HIV infection.

FRANCIS X. BLAIS, DO

Associate Professor of Medicine

Texas College of Osteopathic Medicine

Fort Worth, Tex

\section{HIV resource file AIDS/HIV hotlines}

$\square$ Centers for Disease Control National AIDS Hotline

1-800-342-AIDS (English)

1-800-344-SIDA (Spanish)

1-800-AIDS-TTY (Deaf Access)

(919) 361-8425 (Fax)

$\square$ National AIDS Clearinghouse

PO Box 6003

Rockville, MD 20849-6003

1-800-458-5231 (Reference Specialists)

(301) 217-0023 (International)

1-800-243-7012 (Deaf Access)

(301) 738-6616 (Fax)

-Clinical Trials and Drug Information

1-800-TRIALS-A

$\square$ National Sexually Transmitted Diseases Hotline/American Social Health

Association

1-800-227-8922

$\square$ National Gay Task Force AIDS

Information Hotline

1-800-221-7044

(212) 807-6016 (New York State)

\section{Information Sources}

$\square$ US Public Health Service Public Affairs Office

Hubert H. Humphrey Building

Room 725-H

200 Independence Ave, SW

Washington, DC 20201

(202) 245-6867
Local Red Cross or American Red Cross AIDS Education Office

1730 D St, NW

Washington, DC 20006

(202) $737-8300$

American Association of Physicians for Human Rights

PO Box 14366

San Francisco, CA 94114

(415) 558-9353

\section{AIDS Action Council}

729 Eighth St, SE

Suite 200

Washington, DC 20003

(202) $547-3101$

$\square$ Gay Men's Health Crisis

PO Box 274

132 West 24th St

New York, NY 10011

(212) 807-6655

Hispanic AIDS Forum

c/o APRED

853 Broadway

Suite 2007

New York, NY 10003

(212) $870-1902$ or $870-1864$

\section{Los Angeles AIDS Project}

7362 Santa Monica Blvd

Los Angeles, CA 90046

(213) 876-AIDS

Minority Task Force on Aids

c/o New York City Council of Churches

475 Riverside Dr, Rm 456

New York, NY 10115

(212) $749-1214$ 